\title{
Uma proposta de matriz de avaliação de jogos digitais para o ensino-aprendizagem-uso de língua adicional
}

\author{
Kyria Finardi ${ }^{1}$ \\ Programa de Pós-Graduação em Educação/Programa de Pós-Graduação em Linguística, Universidade Federal \\ do Espírito Santo, Vitória, Espírito Santo, Brasil \\ Gicele Vergine Vieira² \\ Instituto Federal Catarinense, Blumenau, Santa Catarina, Brasil
}

Roberta Leão ${ }^{3}$

Programa de Pós-Graduação em Educação, Universidade Federal do Espírito Santo, Vitória, Espírito Santo

Resumo: Este estudo partiu do pressuposto de que a incorporação de tecnologias no ensinoaprendizagem de línguas adicionais (L2) deve estar associada a práticas pedagógicas que efetivamente favoreçam a aprendizagem. Com esse objetivo, o estudo propõe uma matriz de avaliação de jogos digitais para o ensino-aprendizagem-uso de $L 2$ com onze parâmetros testados em um levantamento de jogos digitais disponíveis online. A primeira etapa do estudo preocupou-se com a proposição da matriz e a segunda com a testagem dos parâmetros propostos por ela. Os resultados do estudo sugerem que a matriz proposta representa um auxílio relevante para professores, aprendizes e usuários de $L 2$ uma vez que reflete pressupostos importantes que subjazem a aquisição e o uso de uma $L 2$, bem como fornece subsídios para seleção de aplicativos que atendam aos objetivos educacionais almejados.

Palavras-chave: Matriz de avaliação; Jogos digitais; Ensino-aprendizagem-uso de L2.

Abstract: This study assumes that the incorporation of technologies in the teaching and learning of additional languages (L2) should be associated with pedagogical practices that effectively favor learning. To this end, the study proposes a matrix for the evaluation of digital games for $\mathrm{L} 2$ teaching-learning-use with eleven parameters tested in a survey of digital games available online. The first stage of the study aimed at the proposal of the matrix and the second with the testing of the parameters proposed by it. The study results suggest that the proposed matrix represents a relevant aid for $L 2$ teachers, learners, and users as it

\footnotetext{
${ }^{1}$ Professora do Departamento de Linguagens, Cultura e Educação e dos Programas de Pós-Graduação em Educação (PPGE) e Linguística (PPGEL) da Universidade Federal do Espírito Santo (UFES), apoio Fapes Universal (Edital 03/2017), ORCID: http://orcid.org/0000-0001-7983-2165.

E-mail: kyria.finardi@gmail.com

2 Professora do quadro permanente do Programa de Mestrado em Educação (PPGE) do Instituto Federal Catarinense. Coordenadora do grupo de pesquisa do CNPq intitulado Linguagem, Cognição e Tecnologia. ORCID: https://orcid.org/0000-0003-3127-0305.

E-mail: gicelevpreb@gmail.com

${ }^{3}$ Graduada em Letras-Inglês (Universidade Federal do Espírito Santo), Mestranda no Programa de Pós-Graduação em Educação (PPGE) da UFES (bolsa FAPES), ORCID: https://orcid.org/0000-0003-3919-5151.

E-mail: robertag.leao@gmail.com
} 
reflects important assumptions that underlie the learning and use of an $L 2$, as well as providing support for the selection of applications that meet the educational goals objectives.

Keywords: Evaluation matrix; Digital games; L2 teaching-learning-use.

\section{Introdução}

Prebianca, Santos Jr. e Finardi (2014a) e Prebianca, Vieira e Finardi (2014b), assim como outros estudiosos da linguagem, entendem a aprendizagem como o produto das interações entre o aprendiz e o mundo que o cerca. Do ponto de vista sociointeracionista, essas interações podem possibilitar experiências de aprendizagem mediadas (FEUERSTEIN, 1997) capazes de promover a reestruturação dos padrões mentais de raciocínio dos aprendizes, ou seja, a modificabilidade ${ }^{4}$ cognitiva estrutural ou aprendizagem.

Segundo Feuerstein e Feuerstein (1994), um dos principais objetivos das experiências de aprendizagem mediada é adaptar o estímulo recebido pelo aprendiz à sua necessidade. Neste caso, o mediador (professor ou artefato tecnológico - software, como proposto por Prebianca, Santos Jr. e Finardi (2014a) torna-se responsável por selecionar e manipular o estímulo (sua intensidade e frequência) de acordo com aquilo que julgar mais apropriado ou relevante para a promoção da modificabilidade cognitiva estrutural de seus aprendizes.

No entanto, é preciso ter em mente que, para Feuerstein e Feuerstein (1994) e Feuerstein (1997), nem toda interação se constitui em uma experiência de aprendizagem mediada. Para tal é preciso que a interação apresente três características básicas. Primeiro, uma experiência de aprendizagem mediada deve ser intencional e demandar um engajamento dos aprendizes, ou seja, precisa apresentar um objetivo pedagógico claro aos que estão interagindo (intencionalidade). Segundo, precisa ser significativa para o aprendiz, possibilitando a troca de valores e experiências de vida na construção de conhecimentos, motivando o aprendiz durante o processo de aprendizagem (significado). E, por último, não deve servir apenas à solução de problemas imediatos, mas possibilitar ao aprendiz a construção de uma rede de conhecimentos interconectados que possam ser aplicados a novas situações de aprendizagem no futuro (transcendência).

Com base na Teoria da Modificabilidade Cognitiva Estrutural proposta por Feuerstein e Feuerstein (1994) e Feuerstein (1997) (e brevemente contextualizada neste artigo), e

\footnotetext{
${ }^{4}$ A modificabilidade cognitiva estrutural pode ser definida como a capacidade do ser humano de modificar, reestruturar suas estruturas cognitivas. Segundo Feuerstein e Feuerstein (1991), essa capacidade refere-se a habilidade do indivíduo de se beneficiar de experiências de aprendizagem, adaptando-se a circunstâncias mais complexas e alterando seu desempenho cognitivo. Em outras palavras, a Teoria da Modificabilidade Cognitiva Estrutural pode ser entendida como uma teoria de aprendizagem, que se dá a partir da interação do indivíduo com o meio, da mediação dos estímulos recebidos e da característica plástica e flexível do aparato cognitivo humano (FEUERSTEIN; FEUERSTEIN, 1991).
} 
considerando o inegável aumento de ferramentas tecnológicas digitais disponíveis no mercado, tanto para lazer quanto para o aprendizado ou prática de línguas adicionais (L2) com características cada vez mais interativas, Prebianca, Santos Jr. e Finardi (2014a) e Prebianca, Vieira e Finardi (2014b), sugeriram que a relevância de um software educacional parece estar relacionada ao grau de interatividade que este oferece ao seu usuário e ao nível de complexidade demandado do aprendiz. Em outras palavras, os autores propuseram que aspectos de usabilidade da interação humano-computador, geralmente levados em consideração apenas na área da computação, mais especificamente, no campo da ciência que estuda a ergonomia (design) de softwares, parecem impactar a percepção dos aprendizes (usuários) a respeito dos softwares educacionais enquanto ferramentas que podem contribuir para a aprendizagem da língua, assim como a qualidade da execução das tarefas propostas por esses softwares (PREBIANCA; SANTOS JR; FINARDI, 2014a, PREBIANCA; VIEIRA; FINARDI, 2014b).

A importância em ter parâmetros que auxiliem a seleção e análise de softwares educacionais, assim como de jogos digitais que possam ser utilizados com objetivos pedagógicos, está no fato de que, segundo esses autores, tais ferramentas podem exercer o papel de mediadores em experiências de aprendizagem mediadas, uma vez que, por meio de técnicas de inteligência artificial, podem selecionar o estímulo fornecido ao usuário de acordo com as suas necessidades específicas. Ademais, as experiências de aprendizagem mediadas por recursos tecnológicos, jogos digitais, neste caso, podem possibilitar que o aprendiz aplique os conhecimentos já adquiridos na solução de desafios e situações-problema a medida em que avança nas fases do jogo, adquirindo, consequentemente, por meio da testagem de hipóteses, comparação e reorganização daquilo que já viu em fases/etapas anteriores, outros conhecimentos ao longo da execução das tarefas propostas pelo jogo. Além disso, o uso de jogos digitais na aprendizagem parece atender a outros dois quesitos importantes quando se trata do uso da tecnologia em contextos educacionais na atualidade: o que diz respeito à necessidade de mobilidade dos aprendizes (ver, por exemplo, FINARDI; LEÃO; AMORIM, 2016a) e o que se refere a uma aprendizagem significativa e motivadora.

Paiva (2017) cita uma pesquisa do Comitê Gestor da Internet no Brasil sobre o uso das tecnologias da informação e comunicação (TICS) realizada em 2014 que revelou uma mudança significativa na forma de acesso à internet nos lares brasileiros, tendo em vista o crescente aumento no número de redes sem fio e no uso de múltiplos dispositivos que permitem usar a rede, como, por exemplo, o celular. Paiva (2017) acredita que, dado esse novo cenário de facilidade de acesso à internet nos dias atuais, o ensino de línguas, em especial, de uma L2, precisa explorar as possibilidades ofertadas pela tecnologia, as quais podem oferecer uma série de benefícios aos aprendizes, entre eles a otimização do tempo. Segundo a autora, "Não existe mais ociosidade se seu celular está em sua mão o tempo todo. A cada intervalo entre uma atividade e outra, é possível interagir, brincar, estudar ou trabalhar com o celular" (p.14). 
Além da facilidade de acesso à rede que permite aos aprendizes de uma L2 estudar, praticar, brincar, jogar, a qualquer hora e em qualquer lugar, Gazotti-Vallim, Gomes e Fischer (2017) alegam que os jogos digitais podem contribuir para uma aprendizagem significativa. Segundo as autoras, os jogos mobilizam emoções por meio de relacionamentos, desafios e atividades de engajamento, cooperação e competição, permitindo feedback rápido e a geração de motivação intrínseca em aprendizes quando incorporados a tarefas pedagógicas. O entendimento de Gazotti-Vallim, Gomes e Fischer (2017) parece estar em sintonia com resultados de pesquisas na área (por exemplo, BUTLER, 2015, CANI; PINHEIRO; SANTIAGO; SOARES, 2107, LEVAY; FALCÃO; DINIZ; DE SOARES, 2015), descritos mais adiante, bem como com os pressupostos da Teoria do Flow (por exemplo, WEISSHEIMER; BRAGA, 2017).

O estado de flow refere-se ao estado mental de indivíduos que, usando suas habilidades, executam tarefas que lhes são desafiadoras, porém prazerosas e que podem Ihes proporcionar uma sensação contínua de satisfação. Se os elementos de gamificação presentes nos jogos digitais elencados por Gazotti-Vallim, Gomes e Fischer (2017) podem servir como fatores motivacionais dos aprendizes por possibilitarem, entre outras coisas, situações desafiadoras e sentimentos de prazer, podemos sugerir, então, que tais elementos podem igualmente conduzi-los a um estado de flow.

Uma vez neste estado, os aprendizes estariam engajados cognitivamente, direcionando seu foco de atenção unicamente para a execução da tarefa e consequentemente, e assim, estariam mais abertos e suscetíveis à aprendizagem. Segundo Weissheimer e Braga (2017), indivíduos em estado de flow estão sujeitos a um nível maior de aprendizagem, uma vez que os processos de formação e consolidação de memórias novas dependem do sistema límbico (que controla as emoções) que é positivamente impactado por estados mentais prazerosos, como é o caso do flow.

Neste sentido, o presente estudo propôs a construção de uma matriz avaliativa de jogos digitais que podem ser utilizados como recursos tecnológicos no processo de ensinoaprendizagem-uso de inglês como L2. O intuito desta matriz é fornecer parâmetros básicos que facilitem a seleção dessas ferramentas de acordo com as necessidades pedagógicas dos aprendizes, daquilo que se pretende ensinar e/ou aprender e da disponibilidade do jogo em termos de gratuidade e acesso.

Vale reforçar que esta matriz representa uma tentativa de ampliação de parâmetros de busca que podem ser empregados em uma fase inicial de levantamento de opções de jogos digitais a serem utilizados por professores e aprendizes, mas não dispensa a análise mais detalhada e aprofundada destas ferramentas após sua seleção, a qual necessita ser embasada em critérios mais específicos que levem em conta a relação entre os aspectos pedagógicos e ergonômicos (de usabilidade na interação humano-computador) dos jogos na promoção da modificabilidade cognitiva estrutural dos aprendizes, conforme defendido por Prebianca, Vieira e Finardi (2014b). 


\section{Jogos digitais e aprendizagem de L2}

A disponibilidade de acesso às tecnologias digitais na forma de computadores, smartphones e tablets com seus inúmeros jogos e aplicativos para o ensino, aprendizagem e uso de línguas adicionais (L2) é consideravelmente maior do que o número de trabalhos realizados para analisar a seleção e os efeitos do uso desses jogos e aplicativos no processo de ensino-aprendizagem-uso de $\mathrm{L} 2$, conforme se pode verificar em uma rápida busca no Google e no Google Acadêmico.

Em relação ao potencial de jogos digitais especificamente voltados ao ensinoaprendizagem de L2, Skehan (2003) afirma que de maneira geral, a pesquisa sobre aquisição de L2 e as aplicações da tecnologia no aprendizado de línguas permaneceram áreas relativamente separadas. Por esse motivo, o autor argumenta que as lições emergentes da pesquisa sobre aquisição de línguas relevantes para o aprendizado de idiomas mediado pela tecnologia são duas. Primeiro, é preciso ter cuidado para garantir que os alunos não realizem ações à custa de seu desenvolvimento linguístico e, segundo, é necessário prover uma variedade de possibilidades de interação e materiais para apoiar o aprendizado de línguas em um contexto de ampla exposição à língua alvo com informações não estruturadas. Nesse sentido, Skehan (2003) aponta para o potencial da abordagem de ensino baseada em tarefas (ABT) no contexto de uso da tecnologia para o ensino de línguas, corroborando a visão de Doughty (2003) de que as escolhas racionais entre as inúmeras opções tecnológicas disponíveis para o ensino de línguas precisam se basear, em parte, em considerações psicolinguísticas.

Nessa linha de raciocínio, em uma análise de aplicativos móveis para a aprendizagem de L2, Kim e Kwon (2012) concluíram que a maior parte das atividades propostas por tais recursos tecnológicos concentra-se em aspectos cognitivos básicos como reconhecimento e compreensão, geralmente abordados por meio de tarefas de compreensão oral e escrita na língua alvo. Esse achado assemelha-se aos resultados das análises conduzidas por Finardi, Prebianca, Schmitt e Andrade (2014c) e Finardi, Prebianca e Schmitt (2016b), os quais demonstraram que o software educacional analisado representava uma relevante ferramenta para o desenvolvimento de habilidades de compreensão (oral e escrita) mas era limitado no tocante ao desenvolvimento de habilidades de produção (oral e escrita).

Outra preocupação em relação ao uso de jogos digitais para o ensino-aprendizagem de L2 está relacionada ao tipo de feedback que esses recursos tecnológicos oferecem aos seus usuários. Prebianca, Santos Jr. e Finardi (2014a), Finardi, Prebianca, Schmitt e Andrade (2014c) e Finardi, Prebianca e Schmitt (2016b), observaram um déficit consistente em relação ao feedback, uma vez que nos softwares educacionais analisados por esses pesquisadores, o retorno recebido pelos aprendizes após a conclusão das atividades era, em geral, limitado e 
focado em questões técnicas, não pedagógicas. Tal fato parece ser decorrente da visão estrutural focada em aspectos léxico-gramaticais da língua, refletidos em atividades com foco apenas em estratégias de tradução (FINARDI; LEÃO; AMORIM, 2016a), não apoiadas nos pressupostos psicolinguísticos (SEKHAN, 2003, DOUGHTY, 2003), sociocognitivos (FEUERSTEIN; FEUERSTEIN, 1994, FEUERSTEIN, 1997) ou de aprendizagem colaborativa, condizentes com abordagens mais modernas do CALL (Computer Assisted Language Learning), do MALL (Mobile Assisted Language Learning) ou, ainda, de abordagens híbridas (ver, por exemplo, FINARDI; PREBIANCA; SCHMITT, 2016b).

Preocupados em compreender a contribuição de softwares educacionais para a aprendizagem de L2 do ponto de vista cognitivo, Prebianca, Santos Jr. e Finardi (2014a) basearam-se nos pressupostos da Teoria da Modificabilidade Cognitiva Estrutural (FEUERSTEIN; FEUERSTEIN, 1994, FEUERSTEIN, 1997) e de ergonomia de softwares (CYBIS; BETIOL; FAUST, 2007) para propor critérios avaliativos levando em consideração (i) a interação entre o software e o aprendiz; (ii) os processos cognitivos envolvidos na execução das atividades propostas pelo software; (iii) as estratégias pedagógicas utilizadas pelo recurso e (iv) a qualidade da interface do software em termos de interação e usabilidade.

Mais tarde, Vieira e Finardi (2018a) conduziram uma meta-análise de estudos que investigaram o uso de softwares educacionais para o ensino-aprendizagem de Inglês como L2, com foco nos aspectos técnicos e pedagógicos a partir dos critérios inicialmente propostos por Prebianca, Santos Jr. e Finardi (2014a). Vieira e Finardi (2018a) concluíram que os resultados dos estudos analisados indicam uma relação direta entre as características pedagógicas e as de interação e usabilidade dos softwares analisados. Os resultados dos estudos analisados por Vieira e Finardi (2018a) sugerem ainda uma limitação em relação ao desenvolvimento pleno de habilidades linguísticas na L2 por meio do uso de softwares educacionais, uma vez que os recursos analisados não promoviam interação e produção oral na língua alvo.

Outra crítica que o uso de aplicativos e smartphones tem recebido em relação ao ensino-aprendizagem-uso de $\mathrm{L} 2$ diz respeito ao fato de que o uso desses aparelhos parece causar distrações ao longo do processo. Ou seja, o tempo de uso (geralmente mais curto) e o fato do usuário poder escolher entre aplicativos com fins pedagógicos e de entretenimento (softwares não educacionais), aliados às restrições de uso de som em espaços públicos, faz com que alguns educadores sintam que tenham que disputar a atenção destinada aos recursos tecnológicos utilizados para diversão com seus objetivos pedagógicos. De fato, Arruda (2013) questiona o uso de tecnologias não educacionais para esses fins uma vez que a linha entre entretenimento e educação pode não ser clara nem desejável para todos.

Rosell-Aguilar (2017), por sua vez, analisou o potencial de aplicativos para a aprendizagem de L2 a partir de uma taxonomia com quatro categorias: tecnologia, pedagogia, experiência do usuário e aprendizagem de L2 levando em consideração os princípios 
cognitivos e interativos de aprendizagem de L2 presentes na observação, negociação de significado, foco na forma e aprendizagem colaborativa (DOUGHTY; LONG, 2003, SKEHAN, 2003). O autor alerta, no entanto, que pode haver um certo grau de sobreposição entre as categorias, como, por exemplo, quando se trata do feedback. Este, por sua vez, pode ser aplicado à categoria de tecnologia (em termos de como é apresentado), de pedagogia (como se relaciona ao ensino), de aprendizagem da L2 (qualidade do feedback) e da experiência do usuário (como o feedback é apresentado na interface ou como pode ser acessado).

Em relação ao uso de jogos para o aprendizado de L2 por crianças, Butler (2015) alerta que apesar do aumento do uso de jogos de computador para o aprendizado de L2 entre crianças, sabemos pouco sobre quais elementos dos jogos auxiliam no processo de aprendizado de línguas. Nesse sentido, o autor analisou os elementos e estruturas de jogos que, do ponto de vista das crianças, tem potencial para o aprendizado da língua. O estudo foi conduzido com 82 alunos, entre 11 a 12 anos de idade, matriculados em uma escola pública do Japão. As crianças discutiram e identificaram os elementos de jogos e os elementos de aprendizado de vocabulário examinando jogos existentes. Em seguida, trabalharam em grupos para propor jogos de computador com base nos elementos que identificaram, apresentando os designs dos jogos em sala de aula e avaliando seus próprios designs e os de seus colegas. Ao todo, foram identificados pelas crianças, 16 elementos de jogos e 8 elementos de aprendizagem. Entre os principais elementos de aprendizagem identificados estão a repetição e revisão de conteúdos, a possibilidade de usar várias modalidades e meios e o controle sobre a própria aprendizagem (autonomia). Os principais elementos de jogos identificados foram o desafio, a fantasia, o autocontrole, o feedback instantâneo e o aplauso.

Na mesma linha, Levay et al. (2015) afirmam que a utilização de jogos digitais no processo de ensino-aprendizagem nas diversas faixas etárias deve estar apoiada em teorias de aprendizagem e abordagens pedagógicas (FELICIA, 2009). Os autores descrevem um estudo sobre a utilização de jogos digitais em dispositivos móveis, com foco no ensino-aprendizagem de inglês para crianças, identificando como esses jogos podem estimular situações pedagógicas relevantes para a aprendizagem. Os resultados desse estudo sugerem que os jogos digitais apresentam-se como um elemento motivacional, contribuindo para a revisão de palavras já aprendidas e para a assimilação inconsciente de vocabulário, na mesma linha do que foi encontrado em Cani et al. (2017) dois anos depois.

Cani et al. (2017) analisaram três aplicativos de dispositivos móveis para a aprendizagem de L2 identificando suas potencialidades e limitações com base na fundamentação teórica sobre gamificação e aprendizagem de línguas mediada pelo computador (CALL). A análise dos três jogos mostrou que há o predomínio de uma abordagem behaviorista de aprendizado da L2. No entanto, segundo aos autores, parece haver também uma tentativa de expandir o ensino de línguas por meio de jogos digitais, visando um contato maior com a língua alvo. 
Vale lembrar, porém, que os aspectos de interatividade presentes na interface dos aplicativos digitais, em especial para uso em smartphones, precisam ser levados em consideração por editores, desenvolvedores e usuários ao avaliar aplicativos existentes ou ao desenvolver seus próprios materiais de aprendizado para dispositivos móveis, conforme advogam Sweeney e Moore (2012). De acordo com esses autores, é preciso que desenvolvedores trabalhem em parceria com professores de línguas e/ou linguistas para criar recursos que possuam o tipo certo de interatividade, utilizem uma mídia adequada e que possam ser projetados para o contexto correto, contemplando o nível apropriado de utilidade e funcionalidade a fim de apoiar um aprendizado autônomo e personalizado (SWEENEY; MOORE, 2012).

Segundo Godwin-Jones (2011), a inserção de smartphones no mercado tem crescido rapidamente em parte pelas características desses aparelhos, que incluem um maior tamanho de telas sensíveis ao toque do usuário, ferramentas de edição de texto e de áudio com alta qualidade, além de ferramentas de gravação, edição e reconhecimento de voz, maior capacidade de armazenamento e conexões mais rápidas. Antes de 2007, os celulares permitiam apenas o uso de aplicativos que vinham previamente instalados pelos fabricantes nos próprios dispositivos (ROSELL-AGUILAR, 2017). Atualmente, no entanto, diversos jogos e aplicativos podem ser baixados de lojas de aplicativos online para diferentes sistemas operacionais, incluindo jogos e aplicativos para aprendizagem e uso de L2 como o Duolingo, Busuu, Hello Talk e Babel, por exemplo.

A ampliação do quantitativo desses aplicativos no mercado expandiu também as possibilidades do que pode ser feito, onde e como, em termos educacionais. Entre essas possibilidades e no tocante ao ensino-aprendizagem-uso de línguas especificamente, RosellAguilar (2017) menciona o fato de os smartphones permitirem o ensino e prática de várias habilidades relacionadas ao ensino-aprendizagem-uso da língua alvo conforme comprovado por vários estudos que reafirmam o potencial desses dispositivos para a aprendizagem de L2 (BURSTON, 2014, GODWIN-JONES, 2011, KIM; KWON, 2012, KIM, 2013, SWEENEY; MOORE, 2012, ROSELL-AGUILAR, 2017) com base nos princípios do MALL.

Sendo assim, Rosell-Aguilar (2017) alega que muitos usuários consideram os aplicativos para aprendizagem de L2 úteis, talvez em virtude de a prática de sala de aula ter avançado para abordagens mais modernas, nas quais os aprendizes podem sentir falta da ênfase em aspectos gramaticais já que a aprendizagem de uma L2 é frequentemente associada à aquisição da estrutura gramatical da língua. Nas salas de aulas tradicionais, por exemplo, não é comum alunos receberem feedback individualizado e alguns usuários de aplicativos podem achar esse retorno importante, mesmo que ele contenha apenas informações técnicas ou o quantitativo de questões respondidas corretamente. Outra razão que parece favorecer o uso de jogos e aplicativos para o ensino-aprendizagem-uso de L2 é a expansão do contato com a língua alvo para além da sala de aula, possibilitando aos 
aprendizes a prática e a aprendizagem em contextos não formais de ensino, respeitando seu tempo e espaço (FINARDI; PREBIANCA; SCHMITT, 2016b).

Entretanto, e como sugerido anteriormente neste artigo, o uso de aplicativos para o ensino-aprendizagem-uso de L2 não está livre de críticas. Segundo Burston (2014), as atividades de ensino-aprendizagem-uso de L2 desses recursos tecnológicos limitam-se, em geral, a replicar o que já era feito com outras tecnologias. Ainda que muitos praticantes do CALL e MALL concordem que o design de atividades para o ensino-aprendizagem-uso de L2 deva ser pensado considerando aspectos pedagógicos (COLPAERT, 2006), muitos aplicativos ainda propõem exercícios e atividades sem instruções, não fornecem feedback adequado e baseiam-se em uma visão estrutural de aprendizagem da língua, dados esses que corroboram a meta-análise sobre o ensino-aprendizagem de Inglês como L2 mediado pelo uso de softwares educacionais conduzida por Vieira e Finardi (2018a).

Apesar das preocupações e críticas em relação à associação de aplicativos, jogos e dispositivos móveis às práticas pedagógicas, em geral, os estudos revisados neste artigo apontam para algumas vantagens no que se refere ao ensino de línguas. Destacam-se, especialmente, as relacionadas à oportunidade de ensinar, praticar ou melhorar as competências linguísticas fora da sala de aula formal. Assim, considerando o aumento da disponibilidade de aplicativos no mercado tecnológico para atividades educacionais e a consequente expansão do contato com a língua alvo além das opções em termos do que pode ser feito, onde e quando, com um único dispositivo, o presente estudo tem como objetivo propor uma matriz de avaliação de jogos digitais para o ensino-aprendizagem-uso de L2, fornecendo subsídios tanto para educadores/professores quanto para usuários/aprendizes na seleção dos aplicativos mais apropriados aos seus objetivos educacionais.

\section{A construção da Matriz Avaliativa}

Este estudo, de caráter qualitativo-descritivo, objetivou elaborar e testar uma matriz de avaliação de jogos digitais para o ensino-aprendizagem-uso de L2. Com essa finalidade, onze parâmetros foram propostos a fim de facilitar a seleção de jogos diversos que possam ser utilizados com fins pedagógicos para o ensino-aprendizagem-uso de L2 por professores e aprendizes. Esses parâmetros, por sua vez, representam uma simplificação dos parâmetros e critérios inicialmente propostos por Prebianca, Santos Jr. e Finardi (2014a) e Prebianca, Vieira e Finardi (2014b), os quais foram amplamente testados por Finardi, Prebianca, Schmitt e Andrade (2014c) e Finardi, Prebianca e Schmitt (2016b).

O estudo foi conduzido em duas etapas. A primeira preocupou-se com a elaboração/proposição da matriz avaliativa e a segunda com a testagem dos parâmetros propostos por ela. Reiterando, alguns parâmetros da matriz que ora se propõe para a busca e 
seleção de jogos digitais que possam servir para fins pedagógicos foram elaborados com base nos estudos de Prebianca, Santos Jr. e Finardi (2014a), Prebianca, Vieira e Finardi (2014b), Finardi, Prebianca, Schmitt e Andrade (2014c) e Finardi, Prebianca e Schmitt (2016b), mais especificamente no instrumento de análise de softwares educacionais proposto por esses pesquisadores, tendo como base a Teoria da Modificabilidade Cognitiva Estrutural, de caráter sociointeracionista, de Feuerstein e Feuerstein (1994) e Feuerstein (1997).

Para tanto, e dado o escopo desta pesquisa, decidiu-se incorporar à matriz avaliativa parâmetros de ordem prática, que pudessem auxiliar professores e aprendizes na escolha de jogos digitais de acordo com suas necessidades, tanto pedagógicas quanto financeiras e de mobilidade, mas sem exigir destes, pelo menos num primeiro momento, um domínio mais aprofundado de questões teórico-metodológicas relativas à aprendizagem em geral, e à aprendizagem de línguas, em particular. Contudo, dado que os parâmetros propostos possuem, por sua vez, um embasamento teórico válido e coerente, acredita-se que, ao fazer uso desta matriz, professores e aprendizes terão acesso a jogos digitais que atendem, ao menos minimamente, a um conjunto de princípios teóricos que nos parece relevante para o processo de ensino-aprendizagem-uso de uma $\mathrm{L} 2$.

O primeiro parâmetro da matriz avaliativa proposta refere-se à natureza do jogo, ou seja, se este é de caráter educativo ou de entretenimento. $O$ segundo refere-se ao gênero do jogo, uma vez que alguns gêneros podem apresentar características mais favoráveis ao ensino-aprendizagem-uso da L2, como, por exemplo, aqueles que permitem maior interação entre os jogadores e aqueles que possibilitam a negociação de significados por meio do uso da L2, em detrimento daqueles que proporcionam pouca ou nenhuma interação ou exigem apenas a compreensão de vocábulos relativamente já conhecidos (itens lexicais emprestados da L2 e de uso comum na língua materna dos aprendizes). Em relação aos diferentes gêneros dos jogos, podemos encontrar, por exemplo, os do tipo aventura, RPG (Role-playing Game), de cartas, MOBA (Multiplayer Online Battle Arena, puzzles (jogos direcionados a solucionar quebra-cabeças), entre outros.

O terceiro parâmetro se relaciona à distribuição dos jogos, se ela é gratuita e/ou paga. Acredita-se que este critério pode influenciar a decisão de usar ou não o jogo, uma vez que nem todos os professores e aprendizes aceitarão ou poderão bancar o custo destas ferramentas digitais, pelo menos não sem conhecer melhor o jogo e suas vantagens enquanto recursos para ensinar e/ou aprender a L2.

O quarto parâmetro diz respeito ao tipo de dispositivo para o qual o jogo está disponível: computador ( $\mathrm{PC}$ ), aparelho celular (smartphones) ou console de videogame. $\mathrm{O}$ quinto parâmetro se refere ao tipo de conexão necessária para utilizar o jogo digital: off-line ou online.

O sexto, sétimo e oitavo parâmetros preocupam-se com os aspectos pedagógicos dos jogos e estão diretamente relacionados aos pressupostos da Teoria da Modificabilidade 
Cognitiva Estrutural (FEUERSTEIN; FEUERSTEIN,1994, FEUERSTEIN, 1997) e aos critérios de usabilidade da interação humano-computador.

O sexto parâmetro, mais especificamente, diz respeito ao tipo de feedback fornecido pelo jogo. Neste estudo, entendemos feedback como uma indicação visual de que há alguma informação sendo processada em determinado momento do jogo, assim como a resposta do game para ações do jogador e tarefas realizadas, conforme proposto por Prebianca, Santos Jr. e Finardi (2014a) e Prebianca, Vieira e Finardi (2014b). Alguns exemplos de respostas podem incluir: "Tarefa realizada com sucesso"; "Loading" (carregando em inglês); "Fase concluída. Passe para a próxima fase", entre outras.

Também observamos, no sétimo parâmetro da matriz avaliativa, (i) se os jogos fornecem proteção contra erros, ou seja, se indicam formas de evitar ou prevenir erros, como, por exemplo, a utilização de dicas e/ou imagens que orientem o jogador a selecionar a ação correta; (ii) se notificam o jogador sobre os erros cometidos de forma clara e objetiva, utilizando algum tipo de sinal como som ou alarme e; (iii) se oferecem oportunidades e informações suficientes para que o usuário identifique e compreenda a razão dos erros cometidos e como corrigi-los (PREBIANCA; SANTOS JR; FINARDI, 2014a, PREBIANCA; VIEIRA; FINARDI, 2014b).

O oitavo parâmetro está relacionado às formas de mediação que os jogos oferecem. Segundo Feuerstein e Feuerstein (1994) e Feuerstein (1997), para que ocorra a aprendizagem é preciso fomentar experiências de aprendizagem mediadas que proporcionem, obrigatoriamente, a mediação de intencionalidade, do significado e da transcendência. Quanto à intencionalidade, este critério de seleção dos jogos avalia se o recurso digital explicita sua intenção educacional e estabelece uma forma de comunicação com o jogador, do qual se espera reciprocidade por meio da participação nas tarefas propostas.

Quanto ao significado, verifica-se se o jogo propõe tarefas relevantes e significativas que aproximam o aprendiz às atividades propostas. No tocante à transcendência, avalia-se se o jogo permite ao jogador desenvolver estratégias que levem a compreensão do seu processo de aprendizagem de maneira que este possa utilizar o conhecimento adquirido em outros contextos de aprendizagem e para resolução/testagem de novas hipóteses em relação ao que está aprendendo.

O nono parâmetro refere-se à língua que o jogo digital utiliza para instrução - língua materna (L1 - português brasileiro) ou língua adicional (L2 - inglês) e o décimo parâmetro, por sua vez, verifica qual (ou quais) aspecto(s) da língua recebe $(m)$ mais ênfase no jogo: gramática, vocabulário, compreensão oral e/ou escrita, entre outros.

Finalmente, o décimo primeiro parâmetro avalia o tipo de ação do usuário (aprendiz) em relação ao jogo, isto é, se esta é controlada, semicontrolada ou autônoma (não controlada). No caso de ações controladas, o jogo não permite ações diferentes do que a que estão programadas para o desenvolvimento da história, missão ou completude de suas 
fases/etapas, como por exemplo, nos jogos da série Monkey Island. Nela, apesar de o jogador poder interagir com personagens e com o cenário de uma forma não linear, existe uma ordem única de resolução dos desafios para se chegar ao objetivo final. Mesmo assim, o jogador só pode interagir com um determinado ambiente caso tenha um objeto específico encontrado na resolução de enigmas anteriores.

Já quando a ação do usuário é semicontrolada, este pode escolher outras opções, dentre as fornecidas pelo game, para o desenvolvimento ou conclusão da história, como nos jogos da série Final Fantasy, em que as ações do jogador irão determinar o desenrolar do enredo do jogo. Nesse caso, o jogador pode escolher não explorar uma determinada parte do cenário, não resolver algum desafio e, até mesmo, escolher se seu personagem terá atitudes heroicas ou não. No entanto, o jogo estabelece um limite de desenvolvimento e conclusões possíveis para a história. Nestes jogos, também há enigmas e ambientes no cenário que só podem ser explorados caso o jogador siga alguns critérios estabelecidos pelo próprio jogo.

Quando a ação do usuário é autônoma significa que o jogo possibilita ao jogador criar suas próprias soluções para o desenvolvimento da história e/ou finalização das fases/etapas. Pode-se encontrar um exemplo deste tipo de ação no jogo Scribblenauts, que permite que o jogador escreva em um campo específico o que a personagem principal utilizará ou em que se transformará para solucionar os desafios propostos. Nesse jogo há ainda a possibilidade de acrescentar ou modificar características dos objetos do cenário e personagens não jogáveis de forma ilimitada, permitindo até que o jogador conclua as etapas de forma cômica e não lógica, usando sua criatividade.

\section{A aplicação da Matriz Avaliativa}

Após a definição dos parâmetros na primeira etapa deste estudo, a segunda etapa dedicou-se a realização de um levantamento de jogos digitais para o ensino-aprendizagemuso de $L 2$ na internet com a finalidade de testar a matriz avaliativa proposta. O levantamento resultou em um total de 56 jogos, os quais foram selecionados de acordo com os parâmetros especificados acima. O Quadro 1 (Apêndice I), apresenta os jogos digitais encontrados a partir dos parâmetros 1, 2, 3 e 4 da matriz avaliativa proposta.

De acordo com os dados do Quadro 1, observamos que as opções de jogos de entretenimento superaram a de jogos educativos, 41 contra 15 respectivamente, na busca por jogos digitais disponíveis no mercado de jogos e aplicativos. Vale mencionar também que, visualmente, os jogos educativos selecionados a partir dos critérios 1, 2, 3 e 4 da matriz avaliadora possuem uma aparência mais infantilizada do que os jogos de entretenimento. Esses jogos, por sua vez, tinham como público-alvo crianças na faixa etária da educação infantil. Sendo assim, pretendiam atender às necessidades de aprendizagem dessa faixa 
etária, para a qual aspectos lúdicos costumam despertar o interesse no aprendizado, além de possibilitar o trabalho com a capacidade motora das crianças (LEVAY, 2015).

No que se refere ao parâmetro 2, foram encontrados 13 jogos do gênero Ensino de Inglês. Estes têm como objetivo principal fornecer ao jogador exercícios de memorização, identificação de vocabulário, associação de vocabulário com imagens, pronúncia e atividades de completar ou organizar frases. Também foram selecionados 10 jogos de Aventura cuja característica predominante é o desenvolvimento do enredo através da solução lógica de enigmas; 12 jogos Role-Playing Game (RPG), em que o jogador assume um papel de um personagem determinante para o desenvolvimento do enredo do jogo; 04 First Person Shooter (FPS), ou seja, jogos de tiro com o cenário apresentado de forma em que o jogador tenha a impressão que faz parte do jogo; 07 de Ação cuja solução de seus desafios exige mais destreza do jogador como combates ou estratégias de guerra; 03 jogos do tipo Multiplayer Online Battle Arena (MOBA), isto é, jogos online em que vários grupos se reúnem com o objetivo de superar o outro; 01 jogo do tipo Casual, gênero também conhecido como Passatempo; 01 Jogo de Carta cujo objetivo é conseguir organizar uma coleção de cartas mais estratégica para vencer outros jogadores ou batalhas de cartas com outros personagens; 01 Massively Multiplayer Online Role-Playing Game (MMORPG) que possui as mesmas características de um jogo de RPG, porém com interação online de jogadores; 02 jogos do tipo FPS/MOBA que possui as características dos dois gêneros; 01 Puzzle/FPS que além das características de um jogo de FPS, também exige soluções de enigmas lógicos e quebra-cabeças; e 01 Puzzle, que se caracteriza pela predominância de quebra-cabeças para a solução de suas etapas.

Notamos que os jogos dos gêneros FPS, Puzzle, MOBA, Casual e Carta utilizam apenas linguagem específica de comando ou feedback, por isso, elaborar tarefas com estes gêneros de jogos demandará maior esforço e mais suporte linguístico do professor. Já a língua em uso está também presente em jogos de outros gêneros, como os de RPG, por exemplo. Esse podem apresentar narrativas bem elaboradas e incluir referências da literatura clássica, como é o caso da série Final Fantasy. Alguns jogos do gênero Aventura trazem ainda elementos de história e cultura geral, como, por exemplo Where in the World is Carmen Sandiego e a série de jogos de Agatha Christie.

De forma geral, as histórias e narrativas podem ser importantes elementos para a promoção do aprendizado da L2, pois estimulam os jogadores a interagir com a interface do jogo e usar a língua para solucionar as situações que se apresentam. Sendo assim, as narrativas, além de estabelecerem um contexto significativo para o desenrolar das ações do jogo, também permitem que os jogadores experimentem situações nem sempre possíveis no mundo 'real' (FARDO,2013, DA SILVA; VIEIRA, 2018).

Ao vivenciar situações desafiadoras como parte das narrativas dos jogos, os aprendizes passam a focar sua atenção em aspectos essenciais para a superação dessas, o que pode levá- 
los a um estado de concentração que desencadeia sensações de prazer e os estimula a seguir adiante no jogo, o chamado estado de flow (WEISSHEIMER; BRAGA, 2016, FARDO, 2013).

Quanto ao critério 3, dos 56 jogos selecionados, 16 são de distribuição gratuita, 39 são pagos e 1 é gratuito apenas para dispositivos móveis. Ao aplicar o parâmetro 4, foram selecionados 18 jogos disponíveis para PC, 14 disponíveis apenas para dispositivos móveis e 07 disponíveis somente para console de videogame. Alguns jogos, no entanto, estão disponíveis para mais de um tipo de dispositivo. Dentre eles, 10 para console de videogame e PC, 02 para console e dispositivo móvel e 04 para console de videogame, dispositivo móvel e PC. Observa-se, a partir dos dados levantados, que 50\% dos jogos está disponível para console, sugerindo a massiva incorporação dos jogos de videogame à vida cotidiana da atualidade.

Em um contexto prático utilizar jogos gratuitos para PC para ensinar uma L2 pode ser mais viável para as escolas que possuem laboratórios de informática, uma vez que alguns jogos pagos não concedem a licença de instalação em mais de uma máquina. Tal fator poderia gerar um custo elevado para o professor, para a escola ou ainda para os aprendizes, especialmente quando se tratar de turmas com grande número de alunos. No caso dos jogos para console, por exemplo, estudos anteriores (MELLO, 2018, CARAMANO, 2017, D’AMBRÓSIO, 2017) apontam para falhas nas políticas públicas para investimento na estrutura das escolas, o que dificulta a execução de aulas que envolvam o uso de tecnologias digitais mais complexas. Neste caso, seria necessário uma sala de vídeo com mais de uma televisão com entrada de áudio e vídeo para console para se trabalhar com vários grupos de alunos ao mesmo tempo, o que parece ser uma realidade distante para algumas escolas e segmentos específicos, como a Educação para Jovens e Adultos (MELLO, 2018, CARAMANO, 2017, D’AMBRÓSIO, 2017).

O Quadro 2 (Apêndice II) apresenta os jogos digitais encontrados a partir da aplicação dos parâmetros 5, 6, 7 e 8 da matriz proposta. Quanto ao parâmetro 5, foram encontrados 39 jogos digitais que podem ser utilizados sem necessidade de conexão à internet, ou seja, offline e 12 que necessitam de conexão, ou seja, é preciso que o jogador esteja online. Cinco (05) jogos, porém, podem ser utilizados de ambas as formas.

No que se refere ao parâmetro 6, 45 jogos apresentaram feedback do tipo processamento, ou seja, ofereceram alguma indicação visual de que informações estavam sendo processadas em determinado momento do jogo. Um (01) jogo apresentou feedback do tipo Resposta, ou seja, fornece informações detalhadas na tela, por meio de frases e desenhos, a cada ação do jogador, permitindo que esse esteja ciente de tudo o que está acontecendo, não somente em seu campo de visão, mas também em relação às ações das personagens não jogáveis ou, até mesmo, de outro jogador. Essas sinalizações mostram o lugar em que as personagens estão, as armas disponíveis e como utilizá-las, entre outras informações relevantes para o jogo. 
O parâmetro 7, por sua vez, verificou se os jogos ofereciam proteção contra erros. Após a aplicação deste parâmetro, 27 jogos não apresentaram nenhum tipo de alerta contra erros. No entanto, 13 jogos ofereceram prevenção contra erros, fornecendo algum tipo de informação que orientava o jogador a tomar decisões mais adequadas para a conclusão das etapas do jogo. Esse é o caso dos jogos da série Pokemon em que ao selecionar um item considerado inadequado para uma determinada situação, o jogo apresenta a frase "There is time and place for everything", indicando ao jogador que é necessário usar outro item ou buscar outra solução para a conclusão da etapa em questão. Sete (07) jogos permitiram a correção dos erros, orientando os jogadores a utilizarem formas mais adequadas ou determinadas pelo jogo para solucionar enigmas ou concluir as fases. Entre estes, alguns jogos mostram a resposta correta e reiniciam a etapa não concluída pelo jogador, como o jogo Speed English Grammar. Além disso, este jogo também oferece suporte gramatical em L2 para que o jogador compreenda as razões pelas quais a sua frase foi considerada inadequada. Ainda de acordo com o parâmetro 7, foram encontrados 09 jogos que emitiram apenas sinais de erros, exibindo sons ou mensagens como "Try Again", "Mission Failed", não oferecendo nenhum direcionamento ao jogador que o deixe consciente sobre qual de suas ações estava errada para o jogo.

Esses dados sugerem que os sistemas de feedback de jogos e aplicativos digitais são deficitários, uma vez que limitam-se a fornecer aos usuários, na maioria das vezes, apenas informações de caráter técnico. A falta de um retorno que enfatize os aspectos pedagógicos das ações dos usuários pode contribuir para a inexistência ou precarização da mediação da transcendência. Em outras palavras, um feedback que aborde questões especificamente ligadas ao conteúdo estudado na L2 pode favorecer a abstração de regras e conceitos por meio da testagem de hipóteses ao usar a L2 durante o jogo. A impossibilidade dessa abstração pode comprometer a capacidade do usuário/aprendiz de generalização e aplicação do que aprendeu em outros contextos de uso da L2, transcendendo o contexto específico e momentâneo do game, conforme advogado por da Silva e Vieira (2018).

Após a aplicação do oitavo parâmetro, 45 jogos não apresentaram nenhum tipo de mediação, incluindo as interações que não conduzem necessariamente às experiências de aprendizagem mediadas. Onze (11) jogos, porém, apresentaram mediação da intencionalidade, pois explicitavam seus objetivos e intenções de forma clara e objetiva, esclarecendo aos jogadores o que precisavam realizar. Vale lembrar que, do ponto de vista sociointeracionista, a mediação do estímulo deve ter objetivos educacionais claros em termos de significado e intencionalidade a fim de promover situações favoráveis para que ocorra a modificabilidade cognitiva estrutural, ou seja, o aprendizado (FEUERSTEIN; FEUERSTEIN, 1994, FEUERSTEIN, 1997).

Pode-se observar, no Quadro 3 (Apêndice III), que após a aplicação dos parâmetros 9, 10 e 11, foram encontrados 23 jogos digitais disponibilizados em L1 e em L2, e 33 disponibilizados somente em L2. Quanto ao parâmetro 10, a maioria dos jogos digitais 
analisados (46 jogos) possui foco na leitura e interpretação textual. Trinta e nove (39) concentram-se no trabalho de compreensão oral, quinze (15) dão foco à escrita em L2, sete (07) abordam o ensino de gramática e aspectos estruturais da língua, três (03) trabalham com ensino-aprendizagem-uso de vocabulário e três (03) focam na produção oral, permitindo que os jogadores se comuniquem uns com os outros quando estiverem online e possuírem microfones e fones de ouvido.

De maneira geral, os dados sugerem que a produção oral em L2 é a habilidade linguística menos prestigiada pelos recursos digitais analisados, corroborando Prebianca, Santos Jr. e Finardi (2014a), Prebianca, Veiria e Finardi (2014b), Finardi, Prebianca, Schmitt e Andrade (2014c) e Finardi, Prebianca e Schmitt (2016b).

\section{Considerações finais}

Este estudo partiu do pressuposto de que a incorporação de tecnologias na educação tem que ser associada a práticas pedagógicas que efetivamente favoreçam a aprendizagem. A fim de contribuir com esse objetivo, este trabalho partiu de estudos que propuseram matrizes de avaliação de tecnologias para o ensino-aprendizagem de L2 para elaborar uma matriz de avaliação de jogos digitais com a mesma finalidade. A matriz avaliativa elaborada neste estudo categorizou jogos em onze parâmetros que foram depois testados por meio de um levantamento de jogos digitais disponíveis online.

Os resultados do estudo sugerem que a matriz proposta representa um auxílio relevante para professores e aprendizes uma vez que fornece subsídios para seleção de aplicativos que atendam aos seus objetivos educacionais. Embora os parâmetros propostos possam ser caracterizados como de ordem prática, estes refletem pressupostos importantes que subjazem a aquisição e o uso de uma L2, fornecendo, assim, a base para uma escolha teórico-metodológica mesmo antes da utilização e avaliação do aplicativo enquanto recurso tecnológico digital relevante para a aprendizagem.

Em outras palavras, ao aplicar a matriz avaliativa, será possível que docentes e aprendizes, escolham, de forma mais informada, os aplicativos que atendam aos seus objetivos, levando-se em conta as características do que se pretende aprender/ensinar, qual aspecto da língua se quer trabalhar, se há ou não conexão com a internet de boa qualidade, se o aplicativo pode ser utilizado de forma gratuita, se ele possui uma interface amigável com bom sistema de feedback, e se, de forma geral, a partir de um ponto de vista mais holístico, pode representar uma ferramenta relevante para o aprendizado naquele determinado momento e estágio do processo de ensino-aprendizagem-uso da L2. 


\section{Referências}

ARÚS, J; RODRÍGUES-ARANCÓN, P; CALLE-MARTÍNEZ, C. A pedagogic assessment of mobile learning applications. Madrid: Conference: ICDE-UNED, p.630-643, 2013.

BUTLER, Y. G. The use of computer games as foreign language learning tasks for digital natives. System, v. 54, p. 91-102, 2015. https://doi.org/10.1016/i.system.2014.10.010

BURSTON, J. The reality of MALL: Still on the fringes. Calico Journal, v. 31, n. 1, p. 103-125, 2014. https://doi.org/10.11139/cj.31.1.103-125

CANI, J; PINHEIRO, I; SANTIAGO, M. E; SOARES, G. Análise de jogos digitais em dispositivos móveis para aprendizagem de línguas estrangeiras. Revista Brasileira de Linguística Aplicada, v. 17, n. 3, p. 455-481, 2017. https://doi.org/10.1590/1984-6398201711880

CARAMANO, E. Proposta de Videoaulas como Organizadores Prévios para uma Aprendizagem Significativa no Ensino de Inglês na EJA. 2017. Dissertação (Mestrado). Faculdade de Ciências. Universidade Federal Paulista, Bauru, 2017.

COLPAERT, J. Toward an ontological approach in goal-oriented language courseware design and its implications for technology-independent content structuring. Computer Assisted Language Learning, v. 19, n. 2-3, p. 109-127, 2006. https://doi.org/10.1080/09588220600821461

CYBIS, W.; BETIOL, A. H.; FAUST, R. Ergonomia e Usabilidade: Conhecimentos, Métodos e Aplicações. São Paulo: Novatec, 2007.

D'AMBROSIO, I. S. S. História em quadrinhos digital como estratégia de desenvolvimento da escrita em inglês. 2017. Dissertação (Mestrado em Educação) - Universidade Federal de Sergipe, São Cristóvão, 2017.

DA SILVA, C. M. DE SIQUEIRA; VIEIRA, G. V. Gamificação e ensino-aprendizagem de Matemática. Trabalho de conclusão de curso de especialização lato sensu. Instituto Federal Catarinense, Câmpus Camboriú, 2018.

DOUGHTY, C. J.; LONG, M. H. Optimal psycholinguistic environments for distance foreign language learning. Language Learning and Technology, v. 7, n. 3, p. 50-80, 2003.

FARDO, M. L. A gamificação como estratégia pedagógica: estudo de elementos dos games aplicados em processos de ensino e aprendizagem. 2013. 104 f. Dissertação (Mestrado em Educação) - Universidade de Caxias do Sul, Caxias do Sul, 2013.

FEUERSTEIN, R. Teoria de la modificabilidad cognitiva estructural. In: Es modificable la inteligencia? Madrid: Bruño, p. 11-23, 1997.

FEUERSTIEN, R; FEUERSTEIN, S. Mediated Learning Experience: a theoretical review. In: Mediated Learning Experience (MLE): theoretical, psychosocial and learning implications. London: Freud Publishing House Ltd., p. 3-51, 1994.

FEUERSTEIN, R.; FEUERSTEIN, S. Mediated Learning Experience: A theoretical review. In R. Feuerstein, P. S. Klein, \& A. J. Tannenbaum (Eds.), Mediated Learning Experience (MLE). Theoretical, Psychological and Learning Implications. London: Freund Publishing House, Ltd. p. 3-51, 1991. 
FELICIA, P. Digital games in schools: Handbook for teachers. Brussels: European Schoolnet EUN Partnership AISBL, 2009.

FINARDI, K. R; LEAO, R. G; AMORIM, G. B. Mobile Assisted Language Learning: Affordances and Limitations of Duolingo. Education and Linguistics Research, v. 2, p. 48-65, 2016a. https://doi.org/10.5296/elr.v2i2.9842

FINARDI, K. R; PREBIANCA, G. V; V; SCHMITT, J. English distance learning: possibilities and limitations of MEO for the Flipped Classroom. Revista Brasileira de Linguística Aplicada, v. 16, p. 181-208, 2016b. https://doi.org/10.1590/1984-639820158527

FINARDI, K. R; PREBIANCA, G. V. V.; SCHMITT, J.; ANDRADE, D. F. Technology, English Language Teaching and Internationalization at a Crossroad: Insights From The Analysis of a Virtual Learning Environment In Brazil. In: International Conference of Education, Research and Innovation, 2014, Sevilha. ICERI2014 Proceedings. Madri: IATED, 2014c. v. 1. p. 1-12.

GARCIA, S. C. A Linguagem em Jogo: Uma Análise da Produção Acadêmica Nacional Sobre a Gamificação no Ensino de Línguas. Hipertextus Revista Digital, v. 17, p. 18-32, 2017.

GODWIN-JONES, R. Mobile apps for language learning. Language Learning \& Technology, v.15, n. 2, p. 2-11, 2011. https://doi.org/10.1080/09571739085200341

JAMIESON, J; CHAPELLE, C. A.; PREISS, Sherry. CALL evaluation by developers, a teacher, and students. CALICO Journal, p. 93-138, 2005. https://doi.org/10.1558/cj.v23i1.93-138

$\mathrm{KIM}, \mathrm{H}$. Emerging mobile apps to improve English listening skills. Multimedia-Assisted Language Learning, v. 16, n. 2, p. 11-30, 2013.

KIM, H; KWON, Y. Exploring smartphone applications for effective mobile-assisted language learning. Multimedia-Assisted Language Learning, v. 15, n. 1, p. 31-57, 2012.

LEFFA, V. Nem tudo o que balança cai: objetos de aprendizagem no ensino de línguas. Polifonia, v. 12, n. 12(2), 2006.

LEVAY, P. Jogos Digitais no Ensino e Aprendizagem de Inglês para Crianças. 2015. Dissertação (Mestrado em Tecnologia e Gestão de Educação a Distância). Unidade Acadêmica de Educação a Distância e Tecnologia. Universidade Federal Rural de Pernambuco. Recife, 2015.

LEVAY, P; FALCÃO, T; DINIZ, J; DE SOUZA, R. Uma experiência de uso de jogos digitais como ferramentas de apoio para aprendizagem de inglês por crianças. In: Anais do Workshop de Informática na Escola. 2015. p. 207. https://doi.org/10.5753/cbie.wie.2015.207

MELLO, E. O Uso de Tecnologias nas Aulas de Língua Inglesa no Ensino Fundamental II em Foz do Iguaçu/PR. 2018. Dissertação (Mestrado em Ensino) - Universidade Estadual do Oeste do Paraná, Foz do Iguaçu, 2018.

PAIVA, V. L. O uso da tecnologia no ensino de línguas estrangeiras: breve retrospectiva histórica. Disponível em http://www.veramenezes.com/techist.pdf, acesso em maio 2017.

PEREIRA, R.; DOS SANTOS, M. Literatura, sociointeracionismo e gamificação: diálogos interdisciplinares a partir de objeto de aprendizagem digital. Sociopoética-Revista do Programa de Pós-Graduação em Literatura e Interculturalidade, v. 1, n. 13, 2015.

PREBIANCA, G. V; SANTOS JUNIOR, V. P; FINARDI, K. R. Analysis of an educational software for language learning: insights from the Theory of Structural Cognitive Modifiability and Human- 
Computer Interaction. DELTA. Documentação de Estudos em Linguística Teórica e Aplicada (PUCSP. Impresso), v. 30, p. 95-114, 2014a. https://doi.org/10.1590/S010244502014000100006

PREBIANCA, G; VIEIRA, M. F. V. FINARDI, K. R. Instrução gramatical na era da tecnologia: investigando diferentes abordagens para o ensino-aprendizagem de Inglês no Ensino Médio Integrado. Signum: Estudos da Linguagem, v. 17, p. 181-214, 2014b. https://doi.org/10.5433/2237-4876.2014v17n1p181

ROSELL-AGUILAR, F. State of the App: A Taxonomy and Framework for Evaluating Language Learning Mobile Applications. CALICO Journal, v. 34, n. 2, 2017. https://doi.org/10.1558/cj.27623

SKEHAN, P. Focus on form, tasks, and technology. Computer Assisted Language Learning, v.16, n. 5, p. 391-411, 2003. https://doi.org/10.1076/call.16.5.391.29489

SWEENEY, P; MOORE, C. Mobile apps for learning vocabulary: Categories, evaluation and design criteria for teachers and developers. International Journal of Computer-Assisted Language Learning and Teaching (IJCALLT), v. 2, n. 4, p. 1-16, 2012. https://doi.org/10.4018/ijcallt.2012100101

TYLER, J. Inglês, Tecnologia e Internacionalização da Educação Superior: Evidências e Reflexões a Partir da Análise de MOOCS. 84p. Dissertação de Mestrado. Programa de PósGraduação em Educação. Universidade Federal do Espírito Santo. Vitória, 2016.

VALLIM, M. A. G.; GOMES, S. T; FISCHER, C. Vivenciando Inglês com Kahoot. The Especialist, v. 38, p. 1-18, 2017. https://doi.org/10.23925/2318-7115.2017v38i1a11

VIEIRA, G. V.; FINARDI, K. R. The Case of EFL: Does Technology Lead to Learning? Raído, v.12, n.30, p. 197-210, 2018a. https://doi.org/10.30612/raido.v12i30.9390

WEISSHEIMER, J; BRAGA, I. Aplicativos Digitais Móveis nas Aulas de Inglês: Efeitos da Gamificação na Aprendizagem e na Motivação dos Aprendizes. Hipertextos Revista Digital, v. 16, p. 91, 2017.

\section{Apêndice I}

Quadro 1 - Levantamento de jogos digitais para o ensino-aprendizagem-uso de L2: parâmetros 1, 2 , 3 e 4

\begin{tabular}{|c|c|c|c|c|}
\hline Nome do Jogo & $\begin{array}{l}\text { Parâmetro } 1 \\
\text { Natureza }\end{array}$ & $\begin{array}{c}\text { Parâmetro } 2 \\
\text { Gênero }\end{array}$ & $\begin{array}{c}\text { Parâmetro } 3 \\
\text { Tipo de } \\
\text { Distribuição }\end{array}$ & $\begin{array}{c}\text { Parâmetro } 4 \\
\text { Tipo de } \\
\text { Dispositivo }\end{array}$ \\
\hline $\begin{array}{l}\text { ABC Kids - Tracing \& } \\
\text { Phonics }\end{array}$ & Educativo & Ensino de Inglês & Gratuita & Móvel \\
\hline $\begin{array}{l}\text { Agatha Christie } \\
\text { (Serie) }\end{array}$ & Entretenimento & Aventura & Paga & Console/PC \\
\hline Baldurs Gates & Entretenimento & RPG & Paga & PC \\
\hline Battlefield (Série) & Entretenimento & FPS & Paga & Console/PC \\
\hline Borderlands (Serie) & Entretenimento & Ação & Paga & Computador \\
\hline Call Of Duty (Série) & Entretenimento & FPS & Paga & Console/PC \\
\hline
\end{tabular}




\begin{tabular}{|c|c|c|c|c|}
\hline Castlevania (Serie) & Entretenimento & Ação & Paga & Console \\
\hline $\begin{array}{l}\text { Counter Strike: } \\
\text { Global Ofensive }\end{array}$ & Entretenimento & FPS & Paga & PC \\
\hline Day of the Tentacle & Entretenimento & Aventura & Paga & PC \\
\hline Dota (Série) & Entretenimento & MOBA & Paga & PC \\
\hline Fall Out (Serie) & Entretenimento & RPG & Paga & PC \\
\hline Feel the Music & Entretenimento & Casual & Gratuita & Movél \\
\hline Final Fantasy (Serie) & Entretenimento & RPG & Paga & $\begin{array}{c}\text { Console/PC/M } \\
\text { óvel }\end{array}$ \\
\hline Fire Emblem & Entretenimento & RPG & $\begin{array}{c}\text { Gratuita apenas } \\
\text { para Dispositivo } \\
\text { Móvel }\end{array}$ & $\begin{array}{c}\text { Console/PC/M } \\
\text { óvel }\end{array}$ \\
\hline $\begin{array}{l}\text { Fun English Learning } \\
\text { Games }\end{array}$ & Educativo & Ensino de Inglês & Gratuita & Móvel \\
\hline $\begin{array}{l}\text { Grammar Smash } \\
\text { English }\end{array}$ & Educativo & Ensino de Inglês & Gratuita & Móvel \\
\hline $\begin{array}{l}\text { Grim Fandango } \\
\text { Remastered }\end{array}$ & Entretenimento & Aventura & Paga & PC \\
\hline $\begin{array}{l}\text { GWENT: The Witcher } \\
\text { Card Game }\end{array}$ & Entretenimento & Card Game & Gratuita & PC \\
\hline Heroes of the Storm & Entretenimento & MOBA & Paga & PC \\
\hline Icewind Dale & Entretenimento & RPG & Paga & PC \\
\hline Infamous (série) & Entretenimento & Ação & Paga & Console \\
\hline KingdomHearts & Entretenimento & RPG & Paga & Console \\
\hline L.A. Noire & Entretenimento & Aventura & Paga & Console/PC \\
\hline League of Legends & Entretenimento & MOBA & Paga & PC \\
\hline $\begin{array}{l}\text { Learn English } \\
\text { Vocabulary Pop Quiz }\end{array}$ & Educativo & Ensino de Inglês & Gratuita & Móvel \\
\hline $\begin{array}{l}\text { Learn English } \\
\text { Vocabulary Words } \\
\text { Offline Free }\end{array}$ & Educativo & Ensino de Inglês & Gratuita & Móvel \\
\hline $\begin{array}{l}\text { Learn English with } \\
\text { Lingo Arcade }\end{array}$ & Educativo & Ensino de Inglês & Gratuita & Móvel \\
\hline $\begin{array}{l}\text { Legend of Zelda } \\
\text { (Serie) }\end{array}$ & Entretenimento & RPG & Paga & Console/Móvel \\
\hline Mass Effect: (Serie) & Entretenimento & RPG & Paga & Console/ PC \\
\hline $\begin{array}{l}\text { Match Up Learning } \\
\text { English }\end{array}$ & Educativo & Ensino de Inglês & Gratuita & Móvel \\
\hline Metal Gear (série) & Entretenimento & Ação & Paga & Console \\
\hline $\begin{array}{l}\text { Monkey Island } \\
\text { (Series) }\end{array}$ & Entretenimento & Aventura & Paga & PC \\
\hline $\begin{array}{l}\text { Monkey Junior: learn } \\
\text { to read }\end{array}$ & Educativo & Ensino de Inglês & Gratuita & Móvel \\
\hline Neverwinter Nights & Entretenimento & MMORPG & Paga & PC \\
\hline Overwatch & Entretenimento & FPS MOBA & Paga & Console/ PC \\
\hline Paladins & Entretenimento & FPS MOBA & Gratuita & PC \\
\hline $\begin{array}{l}\text { Phonics Fun Farm } \\
\text { Games: Letter } \\
\text { Sounds, Sight Words }\end{array}$ & Educativo & Ensino de Inglês & Gratuita & Móvel \\
\hline $\begin{array}{l}\text { Player Unknown's } \\
\text { Battlegrounds }\end{array}$ & Entretenimento & FPS & Paga & Console/ PC \\
\hline
\end{tabular}




\begin{tabular}{|c|c|c|c|c|}
\hline Pokemon (série) & Entretenimento & RPG & Paga & Console/Móvel \\
\hline Portal & Entretenimento & Puzzle FPS & Paga & Console/ PC \\
\hline Riven & Entretenimento & Puzzle & Paga & $\begin{array}{c}\text { Console/PC/M } \\
\text { óvel }\end{array}$ \\
\hline $\begin{array}{l}\text { Saiba Soletrar Inglês } \\
\text { Grátis }\end{array}$ & Educativo & Ensino de Inglês & Gratuita & Móvel \\
\hline Scribblenauts & Educativo & Aventura & Paga & $\begin{array}{c}\text { Console/PC/M } \\
\text { óvel }\end{array}$ \\
\hline $\begin{array}{l}\text { Sherlock Holmes } \\
\text { (Serie) }\end{array}$ & Entretenimento & Aventura & Paga & Console/ PC \\
\hline $\begin{array}{l}\text { Speed English } \\
\text { Grammar }\end{array}$ & Educativo & Ensino de Inglês & Gratuita & Móvel \\
\hline $\begin{array}{l}\text { The Elder Scrolls V: } \\
\text { Skyrim }\end{array}$ & Entretenimento & RPG & Paga & PC \\
\hline The Dig & Entretenimento & Aventura & Paga & PC \\
\hline The Last of Us & Entretenimento & Ação & Paga & Console \\
\hline $\begin{array}{l}\text { The Walking Dead: } \\
\text { The Game }\end{array}$ & Entretenimento & Ação & Paga & Console \\
\hline The Witcher (série) & Entretenimento & RPG & Paga & Console/ PC \\
\hline Uncharted (série) & Entretenimento & Ação & Paga & Console \\
\hline $\begin{array}{l}\text { Valiant Hearts: The } \\
\text { Great War }\end{array}$ & Entretenimento & Aventura & Paga & Console \\
\hline Verb Smash & Educativo & Ensino de Inglês & Gratuita & Móvel \\
\hline Word Scramble ${ }^{\mathrm{TM}}$ & Educativo & Ensino de Inglês & Gratuita & Móvel \\
\hline World of Warcraft & Entretenimento & RPG & Paga & PC \\
\hline
\end{tabular}

Fonte: das autoras

\section{Apêndice II}

Quadro 2 - Levantamento de jogos digitais para o ensino-aprendizagem-uso de L2: parâmetros 5, 6, 7 e 8

\begin{tabular}{|c|c|c|c|c|}
\hline Nome do Jogo & $\begin{array}{c}\text { Parâmetro } 5 \\
\text { Tipo de } \\
\text { Conexão }\end{array}$ & $\begin{array}{c}\text { Parâmetro } 6 \\
\text { Tipo de Feedback }\end{array}$ & $\begin{array}{l}\text { Parâmetro } 7 \\
\text { Tipo de Erro }\end{array}$ & $\begin{array}{c}\text { Parâmetro } 8 \\
\text { Tipo de Mediação }\end{array}$ \\
\hline $\begin{array}{l}\text { ABC Kids - Tracing \& } \\
\text { Phonics }\end{array}$ & Offline & Sem feedback & $\begin{array}{l}\text { Nenhum alerta } \\
\text { de erro }\end{array}$ & $\begin{array}{l}\text { Mediação de } \\
\text { intencionalidade }\end{array}$ \\
\hline Agatha Christie (Serie) & Offline & $\begin{array}{l}\text { Feedback de } \\
\text { processamento }\end{array}$ & $\begin{array}{l}\text { Prevenção } \\
\text { contra erro/ } \\
\text { sinal de erro }\end{array}$ & Nenhuma mediação \\
\hline Baldurs Gates & Offline & $\begin{array}{l}\text { Feedback de } \\
\text { processamento }\end{array}$ & $\begin{array}{l}\text { Prevenção } \\
\text { contra erro }\end{array}$ & Nenhuma mediação \\
\hline Battlefield (Série) & Online/Offline & $\begin{array}{l}\text { Feedback de } \\
\text { processamento/ } \\
\text { Feedback de } \\
\text { resposta }\end{array}$ & $\begin{array}{l}\text { Prevenção } \\
\text { contra erro }\end{array}$ & Nenhuma mediação \\
\hline Borderlands (Serie) & Offline & $\begin{array}{l}\text { Feedback de } \\
\text { processamento }\end{array}$ & $\begin{array}{l}\text { Nenhum alerta } \\
\text { de erro }\end{array}$ & Nenhuma mediação \\
\hline Call Of Duty (Série) & Online/offline & $\begin{array}{l}\text { Feedback de } \\
\text { processamento }\end{array}$ & $\begin{array}{l}\text { Nenhum alerta } \\
\text { de erro }\end{array}$ & Nenhuma mediação \\
\hline Castlevania (Serie) & Offline & $\begin{array}{l}\text { Feedback de } \\
\text { processamento }\end{array}$ & $\begin{array}{l}\text { Prevenção } \\
\text { contra erro }\end{array}$ & Nenhuma mediação \\
\hline
\end{tabular}




\begin{tabular}{|c|c|c|c|c|}
\hline $\begin{array}{l}\text { Counter Strike: Global } \\
\text { Ofensive }\end{array}$ & Online & $\begin{array}{l}\text { Feedback de } \\
\text { processamento }\end{array}$ & $\begin{array}{l}\text { Nenhum alerta } \\
\text { de erro }\end{array}$ & Nenhuma mediação \\
\hline Day of the Tentacle & Offline & $\begin{array}{l}\text { Feedback de } \\
\text { processamento }\end{array}$ & $\begin{array}{l}\text { Sinal de erro / } \\
\text { Correção de erro }\end{array}$ & Nenhuma Mediação \\
\hline Dota (Série) & Online & $\begin{array}{l}\text { Feedback de } \\
\text { processamento }\end{array}$ & $\begin{array}{l}\text { Nenhum alerta } \\
\text { de erro }\end{array}$ & Nenhuma mediação \\
\hline Fall Out (Serie) & Offline & $\begin{array}{l}\text { Feedback de } \\
\text { processamento }\end{array}$ & $\begin{array}{l}\text { Prevenção } \\
\text { contra erro / } \\
\text { Sinal de erro }\end{array}$ & Nenhuma mediação \\
\hline Feel the Music & Online & Sem feedback & Sinal de erro & Nenhuma mediação \\
\hline Final Fantasy (Série) & Offline & $\begin{array}{l}\text { Feedback de } \\
\text { processamento }\end{array}$ & $\begin{array}{l}\text { Nenhum alerta } \\
\text { de erro }\end{array}$ & Nenhuma mediação \\
\hline Fire Emblem & Offline & $\begin{array}{l}\text { Feedback de } \\
\text { processamento }\end{array}$ & $\begin{array}{l}\text { Nenhum alerta } \\
\text { de erro }\end{array}$ & Nenhuma mediação \\
\hline $\begin{array}{l}\text { Fun English Learning } \\
\text { Games }\end{array}$ & Online/Offline & $\begin{array}{l}\text { Feedback de } \\
\text { processamento }\end{array}$ & $\begin{array}{l}\text { Prevenção } \\
\text { contra erro / } \\
\text { Sinal de erro }\end{array}$ & Nenhuma mediação \\
\hline $\begin{array}{l}\text { Grammar Smash } \\
\text { English }\end{array}$ & Offline & $\begin{array}{l}\text { Feedback de } \\
\text { processamento }\end{array}$ & Sinal de erro & $\begin{array}{l}\text { Mediação de } \\
\text { intencionalidade }\end{array}$ \\
\hline $\begin{array}{l}\text { Grim Fandango } \\
\text { Remastered }\end{array}$ & Offline & $\begin{array}{l}\text { Feedback de } \\
\text { processamento }\end{array}$ & $\begin{array}{l}\text { Alerta de erro/ } \\
\text { Correção de erro }\end{array}$ & Nenhuma mediação \\
\hline $\begin{array}{l}\text { GWENT: The Witcher } \\
\text { Card Game }\end{array}$ & Online & $\begin{array}{l}\text { Feedback de } \\
\text { processamento }\end{array}$ & $\begin{array}{l}\text { Nenhum alerta } \\
\text { de erro }\end{array}$ & Nenhuma mediação \\
\hline Heroes of the Storm & Online & $\begin{array}{l}\text { Feedback de } \\
\text { Processamento }\end{array}$ & $\begin{array}{l}\text { Nenhum Alerta } \\
\text { de erro }\end{array}$ & Nenhuma mediação \\
\hline Icewind Dale & Online & $\begin{array}{l}\text { Feedback de } \\
\text { processamento }\end{array}$ & $\begin{array}{l}\text { Prevenção } \\
\text { contra erro }\end{array}$ & Nenhuma mediação \\
\hline Infamous (série) & Offline & $\begin{array}{l}\text { Feedback de } \\
\text { processamento }\end{array}$ & $\begin{array}{l}\text { Nenhum alerta } \\
\text { de erro }\end{array}$ & Nenhuma mediação \\
\hline Kingdom Hearts & Offline & Sem feedback & $\begin{array}{l}\text { Nenhum alerta } \\
\text { de erro }\end{array}$ & Nenhuma mediação \\
\hline L.A. Noire & Offline & $\begin{array}{l}\text { Feedback de } \\
\text { processamento }\end{array}$ & $\begin{array}{l}\text { Prevenção } \\
\text { contra erro / } \\
\text { Sinal de erro }\end{array}$ & Nenhuma mediação \\
\hline League of Legends & Online & $\begin{array}{l}\text { Feedback de } \\
\text { processamento }\end{array}$ & $\begin{array}{l}\text { Nenhum alerta } \\
\text { de erro }\end{array}$ & Nenhuma mediação \\
\hline $\begin{array}{l}\text { Learn English } \\
\text { Vocabulary Pop Quiz }\end{array}$ & Offline & Sem feedback & Sinal de erro & $\begin{array}{l}\text { Mediação de } \\
\text { Intencionalidade }\end{array}$ \\
\hline Legend of Zelda (Serie) & Offline & $\begin{array}{l}\text { Feedback de } \\
\text { processamento }\end{array}$ & $\begin{array}{l}\text { Nenhum alerta } \\
\text { de erro }\end{array}$ & Nenhuma mediação \\
\hline Mass Effect: (Serie) & Offline & $\begin{array}{l}\text { Feedback de } \\
\text { processamento }\end{array}$ & $\begin{array}{l}\text { Prevenção } \\
\text { contra erro / } \\
\text { Sinal de erro }\end{array}$ & Nenhuma mediação \\
\hline $\begin{array}{l}\text { Match Up Learning } \\
\text { English }\end{array}$ & Offline & Sem feedback & $\begin{array}{l}\text { Nenhum alerta } \\
\text { de erro }\end{array}$ & $\begin{array}{l}\text { Mediação de } \\
\text { Intencionalidade }\end{array}$ \\
\hline Metal Gear (série) & Offline & $\begin{array}{l}\text { Feedback de } \\
\text { processamento }\end{array}$ & $\begin{array}{l}\text { Nenhum alerta } \\
\text { de erro }\end{array}$ & Nenhuma mediação \\
\hline Monkey Island (Series) & Offline & $\begin{array}{l}\text { Feedback de } \\
\text { processamento }\end{array}$ & $\begin{array}{l}\text { Sinal de erro/ } \\
\text { Correção de erro }\end{array}$ & Nenhuma mediação \\
\hline $\begin{array}{l}\text { Monkey Junior: learn } \\
\text { to read }\end{array}$ & Offline & Sem feedback & $\begin{array}{l}\text { Nenhum alerta } \\
\text { de erro }\end{array}$ & $\begin{array}{l}\text { Mediação de } \\
\text { Intencionalidade }\end{array}$ \\
\hline Neverwinter Nights & Online & $\begin{array}{l}\text { Feedback de } \\
\text { processamento }\end{array}$ & $\begin{array}{l}\text { Nenhum alerta } \\
\text { de erro }\end{array}$ & Nenhuma mediação \\
\hline Overwatch & Online & $\begin{array}{l}\text { Feedback de } \\
\text { processamento }\end{array}$ & $\begin{array}{l}\text { Nenhum alerta } \\
\text { de erro }\end{array}$ & Nenhuma Mediação \\
\hline
\end{tabular}




\begin{tabular}{|c|c|c|c|c|}
\hline Paladins & Online & $\begin{array}{l}\text { Feedback de } \\
\text { processamento }\end{array}$ & $\begin{array}{l}\text { Nenhum alerta } \\
\text { de erro }\end{array}$ & Nenhuma mediação \\
\hline $\begin{array}{l}\text { Phonics Fun Farm } \\
\text { Games: Letter Sounds, } \\
\text { Sight Words }\end{array}$ & Offline & $\begin{array}{l}\text { Feedback de } \\
\text { processamento }\end{array}$ & Sinal de erro & $\begin{array}{l}\text { Mediação de } \\
\text { Intencionalidade }\end{array}$ \\
\hline $\begin{array}{l}\text { Player Unknown's } \\
\text { Battlegrounds }\end{array}$ & Online & $\begin{array}{l}\text { Feedback de } \\
\text { processamento }\end{array}$ & Sinal de erro & Nenhuma mediação \\
\hline Pokemon (série) & Offline/Online & $\begin{array}{l}\text { Feedback de } \\
\text { processamento }\end{array}$ & $\begin{array}{l}\text { Prevenção } \\
\text { contra erro } \\
\text { /Sinal de erro }\end{array}$ & Nenhuma mediação \\
\hline Portal & Offline & $\begin{array}{l}\text { Feedback de } \\
\text { processamento }\end{array}$ & $\begin{array}{l}\text { Prevenção } \\
\text { contra erro } \\
\text { /Alerta de erro }\end{array}$ & Nenhuma mediação \\
\hline Riven & Offline & $\begin{array}{l}\text { Feedback de } \\
\text { processamento }\end{array}$ & $\begin{array}{l}\text { Nenhum alerta } \\
\text { de erro }\end{array}$ & Nenhuma mediação \\
\hline $\begin{array}{l}\text { Saiba e Soletrar Inglês } \\
\text { Grátis }\end{array}$ & Offline & Sem feedback & $\begin{array}{l}\text { Nenhum alerta } \\
\text { de erro }\end{array}$ & $\begin{array}{l}\text { Mediação de } \\
\text { Intencionalidade }\end{array}$ \\
\hline Scribblenauts & Offline & $\begin{array}{l}\text { Feedback de } \\
\text { processamento }\end{array}$ & $\begin{array}{l}\text { Prevenção } \\
\text { contra } \\
\text { erro/Correção } \\
\text { de erro }\end{array}$ & Nenhuma mediação \\
\hline $\begin{array}{l}\text { Sherlock Holmes } \\
\text { (Serie) }\end{array}$ & Offline & $\begin{array}{l}\text { Feedback de } \\
\text { processamento }\end{array}$ & $\begin{array}{l}\text { Prevenção } \\
\text { contra } \\
\text { erro/Sinal de } \\
\text { erro }\end{array}$ & Nenhuma mediação \\
\hline $\begin{array}{l}\text { Speed English } \\
\text { Grammar }\end{array}$ & Offline & Sem feedback & $\begin{array}{l}\text { Alerta de erro/ } \\
\text { Correção de erro }\end{array}$ & Nenhuma mediação \\
\hline $\begin{array}{l}\text { The Elder Scrolls V: } \\
\text { Skyrim }\end{array}$ & Online/Offline & $\begin{array}{l}\text { Feedback de } \\
\text { processamento }\end{array}$ & $\begin{array}{l}\text { Nenhum alerta } \\
\text { de erro }\end{array}$ & Nenhuma Mediação \\
\hline The Dig & Offline & $\begin{array}{l}\text { Feedback de } \\
\text { processamento }\end{array}$ & $\begin{array}{l}\text { Sinal de erro/ } \\
\text { Correção de erro }\end{array}$ & Nenhuma mediação \\
\hline The Last of Us & Offline & $\begin{array}{l}\text { Feedback de } \\
\text { processamento }\end{array}$ & $\begin{array}{l}\text { Nenhum alerta } \\
\text { de erro }\end{array}$ & Nenhuma mediação \\
\hline $\begin{array}{l}\text { The Walking Dead: } \\
\text { The Game }\end{array}$ & Offline & $\begin{array}{l}\text { Feedback de } \\
\text { processamento }\end{array}$ & $\begin{array}{l}\text { Nenhum alerta } \\
\text { de erro }\end{array}$ & Nenhuma mediação \\
\hline The Witcher (série) & Offline & $\begin{array}{l}\text { Feedback de } \\
\text { Processamento }\end{array}$ & $\begin{array}{l}\text { Nenhum alerta } \\
\text { de erro }\end{array}$ & Nenhuma mediação \\
\hline Uncharted (série) & Offline & $\begin{array}{l}\text { Feedback de } \\
\text { processamento }\end{array}$ & $\begin{array}{l}\text { Nenhum alerta } \\
\text { de erro }\end{array}$ & Nenhuma mediação \\
\hline $\begin{array}{l}\text { Valiant Hearts: The } \\
\text { Great War }\end{array}$ & Offline & Sem feedback & $\begin{array}{l}\text { Nenhum alerta } \\
\text { de erro }\end{array}$ & Nenhuma mediação \\
\hline Verb Smash & Offline & $\begin{array}{l}\text { Feedback de } \\
\text { processamento }\end{array}$ & Sinal de erro & $\begin{array}{l}\text { Mediação de } \\
\text { Intencionalidade }\end{array}$ \\
\hline $\begin{array}{l}\text { Where in the World is } \\
\text { Carmen Sandiego }\end{array}$ & Offline & $\begin{array}{l}\text { Feedback de } \\
\text { processamento }\end{array}$ & $\begin{array}{l}\text { Sinal de erro/ } \\
\text { Correção de erro }\end{array}$ & Nenhuma Mediação \\
\hline Word Scramble ${ }^{\mathrm{TM}}$ & Offline & $\begin{array}{l}\text { Feedback de } \\
\text { processamento }\end{array}$ & $\begin{array}{l}\text { Sinal de erro/ } \\
\text { Correção de erro }\end{array}$ & $\begin{array}{l}\text { Mediação de } \\
\text { Intencionalidade }\end{array}$ \\
\hline World of Warcraft & Online & $\begin{array}{l}\text { Feedback de } \\
\text { processamento }\end{array}$ & $\begin{array}{l}\text { Nenhum alerta } \\
\text { de erro }\end{array}$ & Nenhuma mediação \\
\hline
\end{tabular}

Fonte: das autoras 


\section{Apêndice III}

\section{Quadro 3 - Levantamento de jogos digitais para o ensino-aprendizagem de L2:} parâmetros 9,10 e 11

\begin{tabular}{|c|c|c|c|}
\hline Nome do Jogo & $\begin{array}{l}\text { Parâmetro } 9 \\
\text { Língua de } \\
\text { Instrução }\end{array}$ & Aspecto linguístico em foco & $\begin{array}{l}\text { Parâmetro } 11 \\
\text { Tipo de Ação }\end{array}$ \\
\hline $\begin{array}{l}\text { ABC Kids - Tracing \& } \\
\text { Phonics }\end{array}$ & $\mathrm{L} 2$ & Gramática, estrutural & Controlada \\
\hline Agatha Christie (Serie) & $\mathrm{L} 2$ & Escuta, leitura e interpretação & Semicontrolada \\
\hline Baldurs Gates & L2 & Leitura e interpretação & Semicontrolada \\
\hline Battlefield (Série) & L1 ou L2 & Escuta, leitura e interpretação & Controlada \\
\hline Borderlands (Serie) & L2 & Escuta, leitura e interpretação & Semicontrolada \\
\hline Call Of Duty (Série) & L1 ou L2 & Escuta, leitura e interpretação & Controlada \\
\hline Castlevania (Serie) & L1 ou L2 & Escuta, leitura e interpretação & Controlada \\
\hline $\begin{array}{l}\text { Counter Strike: Global } \\
\text { Offensive }\end{array}$ & L2 & $\begin{array}{l}\text { Escuta, escrita, leitura e } \\
\text { interpretação }\end{array}$ & Controlada \\
\hline Day of the Tentacle & L2 & Escuta, leitura e interpretação & Semi controlada \\
\hline Dota (Série) & L1 ou L2 & $\begin{array}{l}\text { Escuta, escrita, leitura e } \\
\text { interpretação }\end{array}$ & Semi controlada \\
\hline Fall Out (Serie) & L1 ou L2 & Escuta, Leitura e interpretação & Semi controlada \\
\hline Feel the Music & $\mathrm{L} 2$ & Escuta e escrita & Controlada \\
\hline Final Fantasy (Serie) & L1 ou L2 & Leitura e interpretação & Semi controlada \\
\hline Fire Emblem & L1 ou L2 & Escuta, leitura e interpretação & Semi controlada \\
\hline $\begin{array}{l}\text { Fun English Learning } \\
\text { Games }\end{array}$ & L2 & $\begin{array}{c}\text { Escuta, escrita, leitura, } \\
\text { interpretação e Gramática } \\
\text { estrutural }\end{array}$ & Controlada \\
\hline Grammar Smash English & L2 & Gramática, estrutural & Controlada \\
\hline $\begin{array}{l}\text { Grim Fandango } \\
\text { Remastered }\end{array}$ & L2 & Escuta, leitura e interpretação & Semi controlada \\
\hline $\begin{array}{l}\text { GWENT: The Witcher Card } \\
\text { Game }\end{array}$ & L1 ou L2 & $\begin{array}{c}\text { Escuta, escrita, leitura e } \\
\text { interpretação }\end{array}$ & Controlada \\
\hline Heroes of the Storm & L2 & Escrita, leitura e interpretação & Controlada \\
\hline IcewindDale & $\mathrm{L} 2$ & Escuta, leitura e interpretação & Semi controlada \\
\hline Infamous (série) & L1 ou L2 & Escuta, leitura e interpretação & Controlada \\
\hline Kingdom Hearts & $\mathrm{L} 2$ & Escuta, leitura e interpretação & Semi controlada \\
\hline L.A. Noire & $\mathrm{L} 2$ & Escuta, leitura e interpretação & Controlada \\
\hline League of Legends & L1 ou L2 & $\begin{array}{c}\text { Escuta, escrita, leitura e } \\
\text { interpretação e Conversação }\end{array}$ & Semi controlada \\
\hline $\begin{array}{l}\text { Learn English Vocabulary } \\
\text { Pop Quiz }\end{array}$ & L2 & Vocabulário & Controlada \\
\hline $\begin{array}{l}\text { Learn English Vocabulary } \\
\text { Words Offline Free }\end{array}$ & L2 & Vocabulário & Controlada \\
\hline $\begin{array}{l}\text { Learn English with Lingo } \\
\text { Arcade }\end{array}$ & L2 & $\begin{array}{c}\text { Leitura, interpretação, gramática } \\
\text { e estrutural }\end{array}$ & Controlada \\
\hline Legend of Zelda (Serie) & L1 ou L2 & Leitura e interpretação & Controlada \\
\hline Mass Effect: (Serie) & L1 ou L2 & Escuta, leitura e interpretação & Semi controlada \\
\hline $\begin{array}{l}\text { Match Up Learning } \\
\text { English }\end{array}$ & L2 & Gramática, estrutural & Controlada \\
\hline Metal Gear (série) & L2 & Escuta, leitura e interpretação & Controlada \\
\hline
\end{tabular}




\begin{tabular}{|c|c|c|c|}
\hline Monkey Island (Série) & $\mathrm{L} 2$ & Escuta, leitura e interpretação & Controlada \\
\hline $\begin{array}{l}\text { Monkey Junior: learn to } \\
\text { read }\end{array}$ & $\mathrm{L} 2$ & Leitura e interpretação & Controlada \\
\hline Neverwinter Nights & L1 ou L2 & $\begin{array}{l}\text { Escuta, escrita, leitura e } \\
\text { interpretação }\end{array}$ & Semi controlada \\
\hline Overwatch & L1 ou L2 & $\begin{array}{c}\text { Escuta, escrita, leitura, } \\
\text { interpretação e Conversação }\end{array}$ & Semi controlada \\
\hline Paladins & L1 ou L2 & Escuta, leitura e interpretação & Semi controlada \\
\hline $\begin{array}{l}\text { Phonics Fun Farm Games: } \\
\text { Letter Sounds, Sight } \\
\text { Words }\end{array}$ & L2 & $\begin{array}{l}\text { Escuta, leitura, interpretação e } \\
\text { pronúncia }\end{array}$ & Controlada \\
\hline $\begin{array}{l}\text { Player Unknown's } \\
\text { Battlegrounds }\end{array}$ & L1 ou L2 & $\begin{array}{l}\text { Escuta, escrita, leitura e } \\
\text { interpretação }\end{array}$ & Semi controlada \\
\hline Pokemon (série) & L1 ou L2 & Leitura e interpretação & Semi controlada \\
\hline Portal & L1 ou L2 & Leitura e interpretação & Semi controlada \\
\hline Riven & L2 & $\begin{array}{l}\text { Escuta, escrita, leitura e } \\
\text { interpretação }\end{array}$ & Semi controlada \\
\hline $\begin{array}{l}\text { Saiba e Soletrar Inglês } \\
\text { Grátis }\end{array}$ & $\mathrm{L} 2$ & Escuta, escrita e leitura & Controlada \\
\hline Scribblenauts & L1 ou L2 & Escrita, leitura e interpretação & Autonoma \\
\hline Sherlock Holmes (Serie) & L2 & Escuta, leitura e interpretação & Controlada \\
\hline Speed English Grammar & L2 & Gramática, estrutural & Controlada \\
\hline The Elder Scrolls V: Skyrim & $\mathrm{L} 2$ & $\begin{array}{c}\text { Escuta, escrita, leitura e } \\
\text { interpretação }\end{array}$ & Autonoma \\
\hline The Dig & L2 & Escuta, leitura e interpretação & Semi controlada \\
\hline The LastofUs & L1 ou L2 & Escuta, leitura e interpretação & Controlada \\
\hline $\begin{array}{l}\text { The Walking Dead: The } \\
\text { Game }\end{array}$ & L1 ou L2 & Escuta, leitura e interpretação & Semi controlada \\
\hline The Witcher (série) & L1 ou L2 & Escuta, leitura e interpretação & Controlada \\
\hline Uncharted (série) & L1 ou L2 & Escuta, leitura e interpretação & Controlada \\
\hline $\begin{array}{l}\text { Valiant Hearts: The Great } \\
\text { War }\end{array}$ & L2 & Escuta, leitura e interpretação & Controlada \\
\hline VerbSmash & L2 & Gramática, estrutural & Controlada \\
\hline $\begin{array}{l}\text { Where in the World is } \\
\text { Carmen Sandiego }\end{array}$ & L2 & Escuta, leitura e Interpretação & Semi controlada \\
\hline Word Scramble ${ }^{\mathrm{TM}}$ & $\mathrm{L} 2$ & Vocabulário & Controlada \\
\hline
\end{tabular}

Fonte: das autoras

Recebido em: 24/05/2019

Aceito em: 23/10/2019 